\title{
Painless myocardial infarction - a clinical challenge in the emergency department
}

\author{
Dirk Prochnau, MD*; Georg Glück, MD*; Isabelle Holz, MD*; Christof Lascho, $\mathrm{MD}^{\dagger}$; and \\ Ralf Eggers, MD*
}

Keywords: AV block, high sensitive troponin I, painless myocardial infarction, syncope

\section{INTRODUCTION}

Acute myocardial infarction (MI) is diagnosed when the electrocardiogram (ECG) shows ST-segment elevation in at least two contiguous leads or new onset of a bundle branch block in combination with persistent chest discomfort (ST-segment elevation myocardial infarction; STEMI). ${ }^{1}$ In such cases, immediate cardiac catheterization is mandatory to prevent irreversible damage of the heart muscle. Early reperfusion therapy for patients with STEMI improves cardiovascular outcomes. However, some patients with acute MI present without symptoms or with symptoms other than chest pain. ${ }^{2}$ In a multinational, prospective, and observational study including 20,881 patients, $8.4 \%$ of patients with acute coronary syndromes did not have chest pain. ${ }^{3}$ These patients were frequently misdiagnosed and, therefore, undertreated. Those patients have increased hospital mortality rates. ${ }^{3}$ Patients presenting with syncope were at a higher risk of dying.

We report a case of a female patient with acute MI presenting with syncope and AV block without angina or typical ST-segment elevation.

\section{CASE REPORT}

An 86-year-old woman was admitted because of her first syncopal episode, without further symptoms. ECG at admission showed a high-degree AV block with a stable escape rhythm of 50 beats per minute, narrow QRS complexes, an isolated ST elevation in lead III, and an incomplete right bundle branch block (Figure 1). Echocardiography did not reveal any localized wall motion abnormalities and excluded valvular heart disease. There was no history of diabetes mellitus, and the glucose level at admission was within a normal range. Because of hypertension, the patient was on chronic treatment with a beta-blocker, an angiotensin II receptor antagonist, hydrochlorothiazide, and an aldosterone antagonist. The first blood test was unremarkable; the initial highsensitive cardiac troponin I (hsTNI) level (Abbott ARCHITECT STAT high-sensitive troponin I immunoassay, Wiesbaden, Germany) was negative $(7 \mathrm{pg} / \mathrm{ml})$. The patient was scheduled for a pacemaker implantation. A second blood test of biomarkers three hours later showed a marked elevation of hsTNI $(25,290 \mathrm{pg} / \mathrm{ml})$. Immediate cardiac catheterization was performed revealing subtotal ostial stenosis of the right coronary artery (Figure 2A). The left coronary artery had no significant stenosis (Figure $2 \mathrm{~B}$ and $2 \mathrm{C}$ ). Stent implantation was performed successfully (Figure 2D). During the hospital stay, the patient remained asymptomatic, and the AV block disappeared (Figure 3). Five days later the patient could be discharged without further sequelae.

\section{DISCUSSION}

Current guidelines recommend permanent pacing in patients with an acquired second-degree Mobitz type II and high-degree AV block, regardless of symptoms. ${ }^{4}$ In

From *Department of Internal Medicine I, Sophien- and Hufeland-Hospital Weimar, Weimar, Germany; and tDepartment of Anesthesiology and Intensive Care, Sophien- and Hufeland-Hospital Weimar, Weimar, Germany.

Correspondence to: Dr. Dirk Prochnau, Sophien- and Hufeland-Hospital Weimar, Henry-van-de-Velde-Straße 2, 99425 Weimar, Germany; Email: d.prochnau@klinikum-weimar.de

(C) Canadian Association of Emergency Physicians

CJEM 2019;21(4):557-559

DOI 10.1017/cem.2019.11 


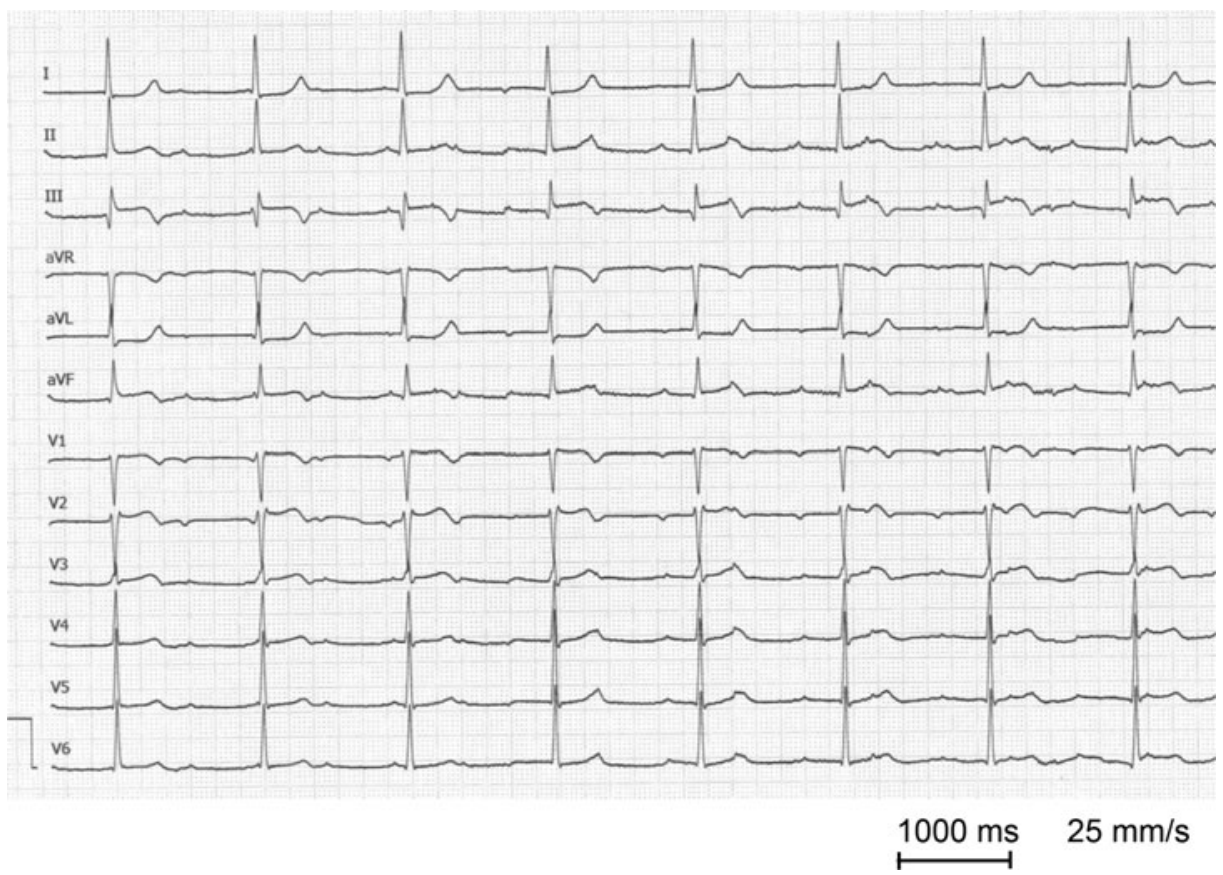

Figure 1. Twelve-lead ECG. ECG at admission with a high-degree AV block and stable escape rhythm of 50 beats per minute, with narrow QRS complexes, an isolated ST elevation in lead III, and an incomplete right bundle brunch block.

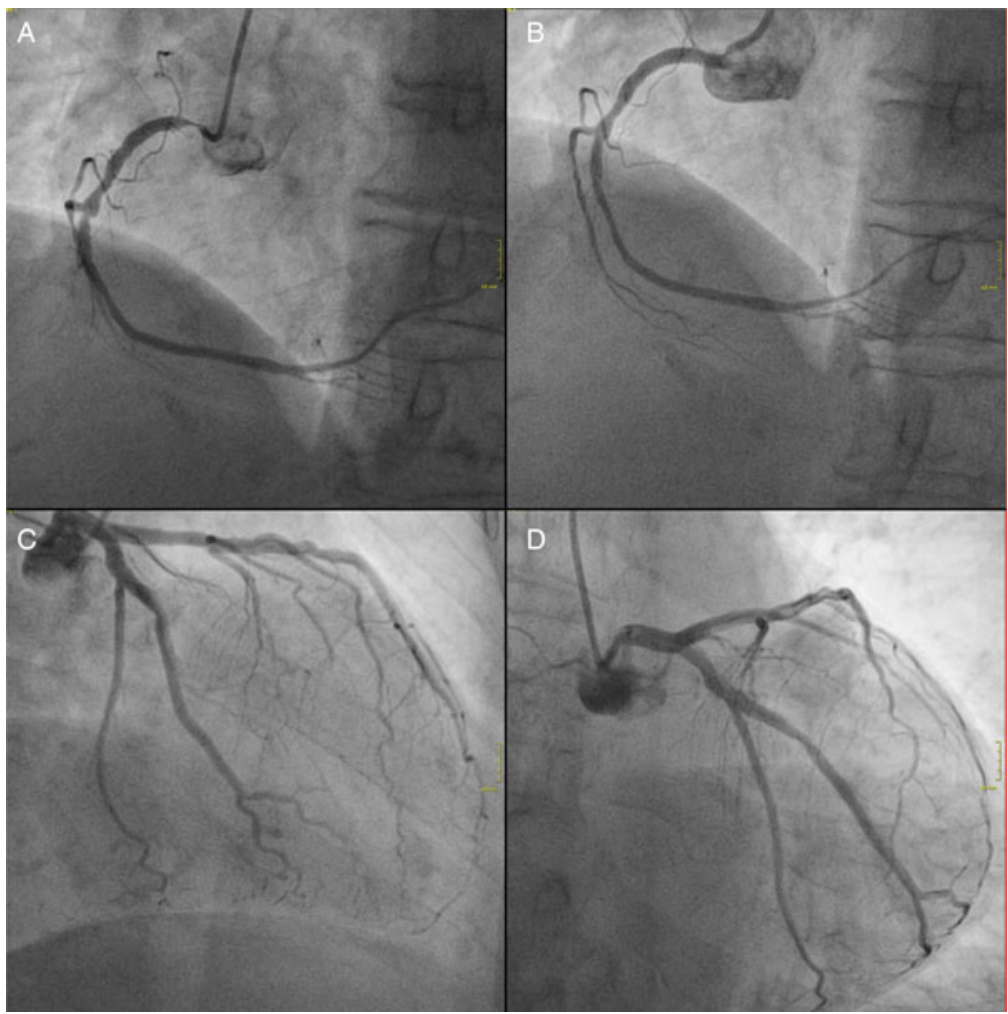

Figure 2. Coronary angiography. (A) Subtotal ostial occlusion of the right coronary artery $\left(40^{\circ} / 0^{\circ}\right.$ projection). (B) Right coronary artery after successful ostial stent deployment. (C and D) Left coronary artery without significant stenosis in two projections (C in $-30 / 0^{\circ}$ projection; $\mathrm{D}$ in $0^{\circ}-30^{\circ}$ projection). 

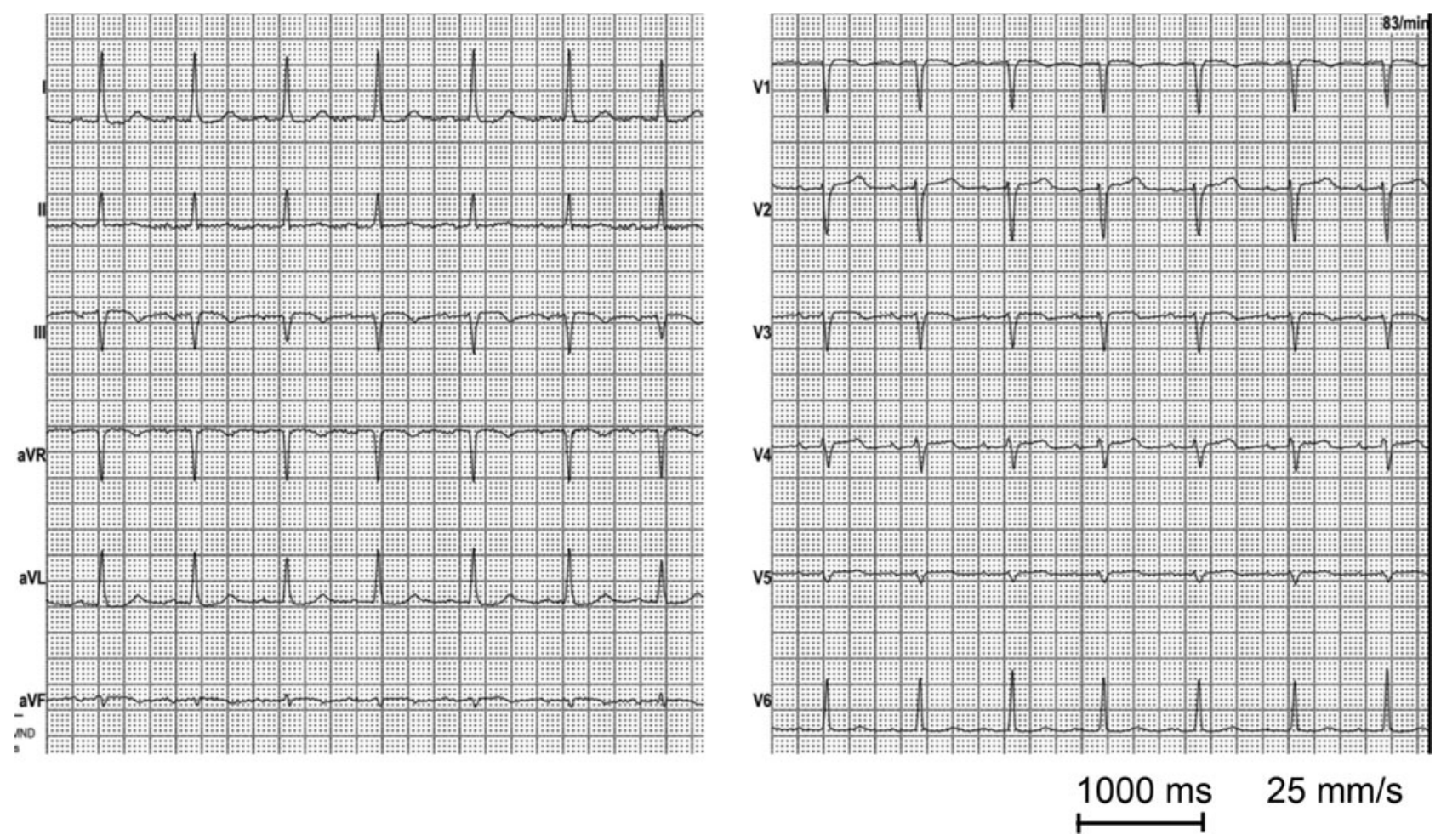

Figure 3. Twelve-lead ECG. ECG at discharge with a sinus rhythm, without an AV block.

patients with a newly identified AV block, transthoracic echocardiography should be performed to exclude apparent structural heart disease. ${ }^{4}$ Furthermore, laboratory testing including thyroid function tests, potassium, and $\mathrm{pH}$ level is recommended. There is no recommendation for routine measurement of the hsTNI level. However, elderly female patients are at a high risk of a silent MI. ${ }^{5}$ It has been shown that painless MI was associated with more adverse events than painful MI because of treatment delay leading to a higher total ischemic burden. ${ }^{6}$ In conclusion, especially in the emergency department (ED), we should consider silent $\mathrm{MI}$ in all high-risk patients. Measurement of hsTNI in such high-risk groups is a simple tool that might help to improve diagnostic and treatment efficiency. Immediate adequate treatment, in our case, stenting of the right coronary artery as the target lesion, prevents inappropriate therapy. In this patient, unnecessary pacemaker implantation was prevented, and the prognosis of this patient might have been improved.

Acknowledgements: All authors take responsibility for all aspects of the reliability and freedom from bias of the data presented and their discussed interpretation.

Competing interests: The authors have no conflicts of interest to declare.

\section{REFERENCES}

1. Roffi M, Patrono C, Collet JP, Mueller C, Valgimigli M, Andreotti F, et al. [2015 ESC Guidelines for the management of acute coronary syndromes in patients presenting without persistent ST-segment elevation. Task Force for the Management of Acute Coronary Syndromes in Patients Presenting without Persistent ST-Segment Elevation of the European Society of Cardiology (ESC)]. G Ital Cardiol (Rome) 2016;17(10):831-72.

2. Deedwania PC, Carbajal EV. Prevalence and patterns of silent myocardial ischemia during daily life in stable angina patients receiving conventional antianginal drug therapy. Am $\mathcal{F}$ Cardiol 1990;65(16):1090-6.

3. Brieger D, Eagle KA, Goodman SG, Steg PG, Budaj A, White K, et al.; GRACE Investigators. Acute coronary syndromes without chest pain, an underdiagnosed and undertreated high-risk group: insights from the Global Registry of Acute Coronary Events. Chest 2004;126(2):461-9.

4. Kusumoto FM, Schoenfeld MH, Barrett C, Edgerton JR, Ellenbogen KA, Gold MR, et al. 2018 ACC/AHA/HRS guideline on the evaluation and management of patients with bradycardia and cardiac conduction delay: executive summary. Circulation 2018;2018:CIR0000000000000627.

5. Cho JY, Jeong MH, Ahn YK, Kim JH, Chae SC, Kim YJ, et al. Comparison of outcomes of patients with painless versus painful ST-segment elevation myocardial infarction undergoing percutaneous coronary intervention. Am f Cardiol 2012;109(3):337-43.

6. Pek PP, Loy EY, Wah W, Ho AF, Zheng H, Fook-Chong SM, et al. Reperfusion treatment delays amongst patients with painless ST segment elevation myocardial infarction. CFEM 2017;19(5):355-63. 